\title{
Renaissance of the autologous pubovaginal sling
}

\author{
Gamal M. Ghoniem ${ }^{1}$ - Diaa E. E. Rizk ${ }^{2}$
}

Received: 21 September 2017 / Accepted: 8 November 2017 / Published online: 22 November 2017

(C) The International Urogynecological Association 2017

Autologous tissue has been used to treat female stress urinary incontinence (SUI) for almost a century, with many operative modifications introduced throughout the years of the standard procedure known as pubovaginal sling (PVS) [1]. Currently, either rectus fascia or fascia lata are used to create a hammock on which the bladder neck and urethra can rest. The use of other biological tissues, however, failed the test of time, albeit the earlier good results. During the past decade, the US Food and Drug Administration (FDA) public communications caused a dramatic increase in litigation and malpractice claims related to synthetic mesh use for midurethral slings (MUS). As a direct result, the use of these slings significantly decreased, partly because their production was abandoned by many manufactures, and partly due to the growing concern among women about having this type of surgery [2]. This factor was responsible for the resurgence of interest in recent years to adopt the autologous PVS or fascial sling as an alternative surgical option for treatment of SUI when there is concern about tissue quality, possible litigation, and when patients refuse synthetic slings. The low rate of adverse events with PVS, such as vaginal erosion, infection, and urethral damage attributable to synthetic mesh, also supported this decision. The PVS can thus be used in patients when placement of a synthetic mesh sling is contraindicated, such as with concomitant urethral diverticulectomy, repair of urethrovaginal fistulae, prior pelvic radiation, or history of prior or concurrent urethral mesh erosion [2]. Traditionally, the PVS was reserved for recurrent SUI due to intrinsic sphincteric deficiency because of the technical difficulty involved and the special surgical skills required for performing the procedure. More recently, the operation has been successfully used for primary SUI, as continence rates were better with greater patient satisfaction despite the higher

Gamal M. Ghoniem

gghoniem@uci.edu

1 Department of Urology, University of California-Irvine, 333 City Blvd. West, Ste 2100, Orange, CA 92868, USA

2 Department of Obstetrics and Gynecology, College of Medicine and Medical Sciences, Arabian Gulf University, Manama, Bahrain incidence of postoperative voiding dysfunction compared with Burch colposuspension [3]. This finding is supported by results of a recent meta-analysis of 15,855 patients showing that both synthetic and PVS had similar objective cure rates that were superior to Burch colposuspension [4].

SUI in women should be considered as a continual process directly related to internal sphincter competence. In women with SUI and normally functioning internal sphincter, a higher intra-abdominal pressure is required to forcibly open the bladder outlet, but a lower increase of abdominal pressure will cause outlet opening and incontinence if the sphincter function is compromised. Positioning an anti-incontinence sling at the bladder neck and proximal urethra provides support to the bladder outlet with increased intra-abdominal pressure, thus restoring continence. Using videofluorourodynamic studies with the patient in the standing position, a moderate increase of posterior urethral pressure was observed with SUI that is enough to maintain continence during rest. The specific dynamic action of the sling was, however, demonstrated during increased abdominal pressure with coughing and Valsalva maneuver. The rectus muscle contracted, pulling the sling slightly forward (anteriorly), with rotation of the bladder base posteriorly and inferiorly causing compression and kinking of the bladder outlet and preventing incontinence. Understanding this selective dynamic continence mechanism is essential to the pelvic surgeon to avoid excessive tightening of the sling, which will lead to voiding dysfunction. If the high residual urine or urinary retention resulting from voiding dysfunction does not resolve after 3 months postoperatively, a sling incision may be required. In certain women with severe SUI due to damaged or impaired internal sphincteric mechanism, an occlusive sling or crossover bladder-neck wrap sling may be required. Examples of these cases include extensive sphincter fibrosis following multiple pelvic surgery or neurogenic patients with a wide-open bladder neck.

Pelvic reconstructive surgeons are expected to discuss surgical options with women with SUI in detail so that an informed decision can be made by both parties regarding which surgery to choose. The pros and cons of PVS, including additional incision to harvest the fascia and more storage 
symptoms than with mesh slings, should be addressed. The newer generation of surgeons, however, have little or no exposure to the complex technical skills needed to perform a successful PVS. Teaching this procedure is thus essential in any fellowship training program in female pelvic medicine and reconstructive surgery, because the PVS is gaining momentum as a primary therapeutic option for SUI. In fact, a recent report on the international minimum acceptable training standards for obstetrics and gynecology residents and general providers has given PVS the same weight as that of synthetic sling and Burch colposuspension regarding competency level in surgical skills. Cadaveric courses that offer numerous opportunities for practice and hands-on experiences via a mentor-mentee dynamic model can provide the most suitable platform for acquiring these skills, similar to other antiincontinence procedures.

The autologous PVS remains a valuable surgical option for both primary and recurrent SUI in women, showing high cure rates and minimal side effects. The operation restores continence through a dynamic hammock mechanism that works mainly during increased intra-abdominal pressure, with minimal effect on resting bladder-outlet resistance. With the recent decline in the use of synthetic MUS, the demand for PVS is expected to increase in urogynecological practice, and this requires specific training in procedural surgical skills during fellowship programs.

\section{Compliance with ethical standards}

Conflict of interest Gamal Ghoniem: Research grants: Astellas, Allergen and Aquinox. Dia Rizk: None

\section{References}

1. Ghoniem GM and Shaaban A (1994) Sub-urethral slings for treatment of stress urinary incontinence. Int Urogyn J 5: 228-239.

2. Ghoniem G, Hammett J. Female pelvic medicine and reconstructive surgery practice patterns: IUGA member survey. Int Urogyn J. 2015;26(10):1489-94.

3. Brubaker L, Richter HE, Norton PA, et al. 5-year continence rates, satisfaction and adverse events of Burch urethropexy and fascial sling surgery for urinary incontinence. J Urol. 2012;187:1324-30.

4. Fusco F, Abdel-Fattah M, Chapple CR, et al (2017). Updated Systematic Review and Metaanalysis of the Comparative Data on Colposuspensions, Pubovaginal slings, and Midurethral tapes in the Surgical Treatment of Female Stress Urinary Incontinence. Eur Urol https://doi.org/10.1016/j.eururo.2017.04.026. 